\title{
Improvement of Dyeing and Weighting Properties of Silk Via Grafting with Acrylic (AA) and Glycidyl Methacrylate (GMA)
}

\author{
S. H. Abdel Fattah*, A. M. Ramadan, S. M. Abo El-Ola, M. Abdelkreem \\ Textile Research Division, National Research Centre Dokki, Giza, Egypt
}

Email address:

dr.salehh@yahoo.com (S. H. A. Fattah)

To cite this article:

S. H. Abdel Fattah, A. M. Ramadan, S. M. Abo El-Ola, M. Abdelkreem. Improvement of Dyeing and Weighting Properties of Silk Via Grafting with Acrylic (AA) and Glycidyl Methacrylate (GMA). Science Journal of Chemistry. Vol. 3, No. 1, 2015, pp. 11-17. doi: $10.11648 /$ j.sjc.20150301.12

\begin{abstract}
Copolymerization of acrylic acid (AA) and /or glycidyl methacrylate (GMA) with silk was carried out using $\mathrm{H}_{2} \mathrm{O}_{2} / \mathrm{Cu}^{2+}$ reduced system. The results revealed that increasing $\mathrm{H}_{2} \mathrm{O}_{2}$ concentrations enhance polymerization up to $0.078 \mathrm{meq} / \mathrm{l}$ and also decreased the (TC) and (GY). Presences of $\mathrm{Cu}^{+2}$ ions up to $5 \mathrm{mmol} / \mathrm{l}$ accelerate the polymerization of (GY), (GE) and (TC). Increasing GMA and AA concentrations within the range studied were accompanied by enhancing (GY) in contrast with the (HP), (GY), (TC), and (GE) while the (HP) decrease. Crease recovery angle increased from $233^{\circ}$ to $324^{\circ}$ in the dry state. Dyeability as well as weighting and moisture regain properties were also improved.
\end{abstract}

Keywords: Silk, Grafting, Crease Recovery, Dyeing, Moisture Regain

\section{Introduction}

Graft copolymerizations of synthetic as well as natural fibers with the aim of imparting specific, desirable properties are the main developments in macromolecular chemistry (13 ). The eliminations of some undesirable proprieties of silk such as photo - yellowing, crease recovery and weighting need to be improved by coating and / or grafting of vinyl monomers in order to compensate for the loss resulting from degumming (4-7).

In this article, we present the results of graft copolymerization of silk using both acrylic acid (AA) and / or glycidyl methacrylate (GMA) and their mixtures. Hydrogen peroxide /copper sulphate redox initiator is employed to induce polymerization. Factors affecting the polymerization process are studied and evaluated. Meanwhile Improving dyeing and weighting properties of silk are studied at the technological level.

\section{Materials and Methods}

\subsection{Materials}

Silk fabric was used after sericin was removed by conventional alkaline degumming, followed by washing with distilled water and air drying. Glycidyl methacrylate (GMA), acrylic acid (AA), hydrogen peroxide, copper sulphate and methyl ethyl ketone were of laboratory grade chemicals. The dyes used were supranol Red G.W, supranol Blue BLW and Remazol Brilliant Blue.

\subsection{Methods}

\subsubsection{Grafting Procedure}

Graft copolymerization reaction was carried out on silk fabric in a medium containing the monomer, copper sulphate and hydrogen peroxide using fabric to liquor ratio 1:100. Erlenmeyer Stopper flask was used for this purpose. The flask containing all reaction media was placed in a thermostatic water bath at the desired reaction temperature $\left(30-80{ }^{\circ} \mathrm{C}\right)$. The polymerization was allowed to proceed for different times ranging from 30 to $150 \mathrm{~min}$. The reaction solution was shaken occasionally. The samples were then removed, washed well with warm water. Dilute solution of 2 $\mathrm{gm} \Lambda$ of nonionic detergent was used to remove loosely adhered homopolymers, thoroughly washed and dried. The dried samples were washed repeatedly with methyl ethyl ketone till constant weight was obtained. Calculation of the percentage of homopolymer (HP), graft efficiency (GE \%), graft yield (GY \%) and the total conversion (T.C \%) based on the dry weight were calculated as follows : 


$$
\mathrm{GY} \%=\left[\left(\mathrm{Wg}-\mathrm{W}_{\mathrm{O}}\right) \div \mathrm{W}_{\mathrm{O}}\right] \mathrm{X} 100
$$

Where:

$\mathrm{Wg}$ : is the weight of grafted silk.

Wo: is the weight of ungrafted silk.

$\mathrm{HP} \%=($ dry weight of homopolymer $\div$ weight of polymer $) \times 100$

$$
\begin{gathered}
\mathrm{GE} \%=[\text { weight of grafted polymer } /(\text { weight of grafted } \\
\text { polymer }+ \text { weight of homopolymer })] \times 100
\end{gathered}
$$

$\mathrm{TC} \%=[($ weight of grafted polymer + weight of homopolymer) / weight of monomer] $\times 100$.

\subsubsection{Dyeing Techniques}

\section{(i) Acid Dyes}

Dyeing was performed using an exhaustion method by immersing silk samples in a dye bath containing $2 \%$ (o.w.f) using fabric to liquor ratio of 1:100. The acidity of the bath was adjusted to $\mathrm{p} \mathrm{H} 4$ using acetic acid. The dyeing was started at $40{ }^{\circ} \mathrm{C}$ and the temperature was gradually increased up to $90{ }^{\circ} \mathrm{C}$ in one hour. The dyed samples were thoroughly rinsed with cold water, soaped at $50{ }^{\circ} \mathrm{C}$ for 30 minutes and finally dried at ambient conditions. Unfixed dye was extracted with $50 \%$ dimethylformamide for 30 minutes at the boil.

\section{(ii) Reactive Dye}

Dyeing was carried out as mentioned before except that $10 \%$ (o.w.f) Glauber salt was added and the $\mathrm{pH}$ was adjusted at 8.5 .

\subsubsection{Moisture Regain}

The silk samples were conditioned at room temperature in desiccators containing a saturated solution of sodium nitrite for 4 days to acquire $63 \%$ relative humidity. The moisture regain (MR) was calculated as follows:

$$
\mathrm{MR} \%=\left[\left(\mathrm{W}-\mathrm{W}_{\mathrm{O}}\right) \div \mathrm{W}_{\mathrm{O}}\right] \times 100
$$

Where:

$\mathrm{W}$ is the weight of the conditioned silk.

Wo is the weight of the dry silk.

\subsubsection{Crease Recovery}

Crease recovery angles of silk were measured using the apparatus type FF (Metrimpex) for a creasing period of 10 minutes. Creasing angles were expressed as the sum of the crease recovery angle of warp $(\mathrm{W})$ and weft $(\mathrm{F})$.

\section{Results and Discussion}

\subsection{Reactions Mechanisms}

Previous reports (8-10) have disclosed that hydrogen peroxide together with metallic ions of $\mathrm{Cu}^{+2}$ forms a very effective system capable of initiating vinyl graft polymerization onto various macromolecules such as wool or cellulose. It appears of interest to establish the influence of such ions on grafting of silk fabrics with (GMA) and (AA) in presence of hydrogen peroxide as initiator silk is presented by $\mathrm{S}-\mathrm{H}$ and the monomer

$$
\begin{gathered}
\mathrm{H}_{2} \mathrm{O}_{2} \rightarrow \mathrm{H}^{+}+\mathrm{H}_{2} \mathrm{O}^{-} \\
\mathrm{Cu}^{+2}+\mathrm{HO}_{2}^{-} \rightarrow \mathrm{Cu}^{+}+\mathrm{H}_{2} \mathrm{O} \\
\mathrm{H}_{2} \mathrm{O}^{-}+\mathrm{H}_{2} \mathrm{O}_{2} \rightarrow \mathrm{OH}^{-}+\mathrm{H}_{2} \mathrm{O}+\mathrm{O}_{2} \\
\mathrm{~S}-\mathrm{H}+\mathrm{OH}^{-} \rightarrow \mathrm{S}^{-}+\mathrm{H}_{2} \mathrm{O} \\
\mathrm{S}^{\cdot}+\mathrm{M} \rightarrow \mathrm{SM}^{-} \\
\mathrm{OH}^{-}+\mathrm{M} \rightarrow \mathrm{M}^{-}-\mathrm{OH}
\end{gathered}
$$

The reaction mechanisms suggested by the above reaction scheme show that $\mathrm{H}_{2} \mathrm{O} 2$ is converted to $\mathrm{OH}^{-}$and $\mathrm{H}_{2} \mathrm{O}$ radicals in presence of $\mathrm{Cu}^{+}$when $\mathrm{H}_{2} \mathrm{O}_{2}$ is present in excess over $\mathrm{Cu}^{+}$ ions (eq.1-3). The radicals attack silk macromolecules through abstracting hydrogen atom, thereby giving rise to silk macroradicals capable of initiating grafting of AA and /or GMA (eq.4). Also the grafting and homopolymer chains are propagated through addition of monomer molecules till termination step (eq.5-6). With the above mechanisms, it is obvious that silk, $\mathrm{H}_{2} \mathrm{O}_{2}$, copper sulphate, monomer, water polymerization system will depend on various factors affecting the magnitude of graft yield, graft efficiency, homopolymer as shown from the following results and their discussions.

\subsection{Initiator Concentration}

\subsubsection{Hydrogen Peroxide Concentration}

Figure $1(\mathrm{a} \& \mathrm{~b})$ shows the influence of polymer yield $\%$ as a function of hydrogen peroxide concentration when (GMA) and (AA) were used. Obviously, the GY increases sharply initially to the maximum with increasing the concentration up to $0.078 \mathrm{meq} / \mathrm{l}$ and then decreases. It is a typical behavior observed in grafting processes occurring via chain transfer mechanism (11-12). This may be referred in grafting to the possibility of increasing silk macroradicals through the interaction of free radicals with the reactive groups of silk. However the higher concentrations of $\mathrm{H}_{2} \mathrm{O}_{2}$ will give more free radicals, as well as more homopolymer and the graft percentage will decrease as shown in reaction mechanism (Figure 1). The results of GE\% display trends similar to those brought about the grafting formation which is observed to be the minimum at $\mathrm{H}_{2} \mathrm{O}_{2}$ concentration 0.078 meq / 1 then increases gradually.

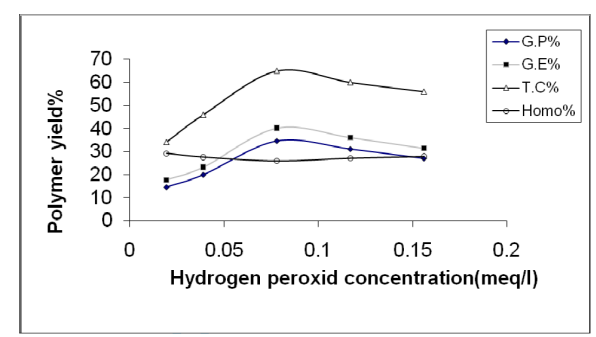

Fig. 1(a). Effect of hydrogen peroxide concentration on the polymer yield \% of grafted silk using glycidyl methacrylate. 


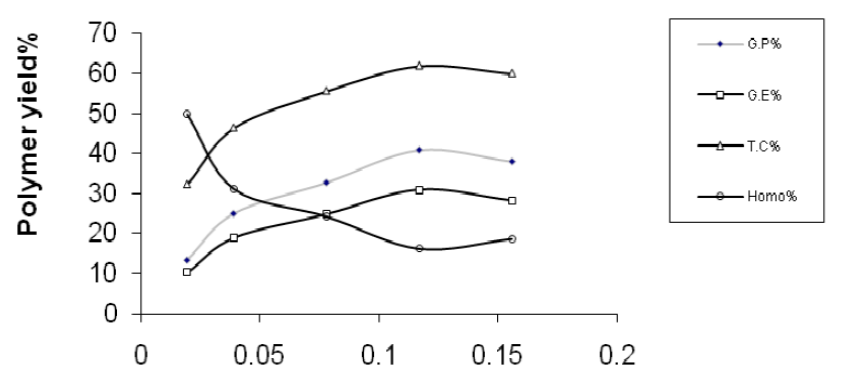

Hydrogen peroxide concentration(meq/l)

Fig. 1(b). Effect of hydrogen peroxide concentration on the polymer yield of grafted silk using acrylic acid as monomers

Conditions: 5\% GMA (owf), reaction time $1 \mathrm{hr}$, temperature $80{ }^{\circ} \mathrm{C}$, liquor ratio $1: 100$, copper sulphate 6 $\mathrm{mmol} / 1$.

Conditions: $5 \%$ AA (o. w. f), time $1 \mathrm{hr}$, , temperature $80{ }^{\circ} \mathrm{C}$, liquor ratio 1:100; copper sulphate $6 \mathrm{mmol} / \mathrm{l}$.

\subsubsection{Copper ion Concentration}

Figure 2 ( $\mathrm{a} \& \mathrm{~b})$ shows the dependence of the polymer yield as a function of increasing initiator concentration of $\mathrm{Cu}^{+2}$ ions in the free radical polymerization medium for grafting GMA and AA onto silk fibroin. It is obvious that the graft yield increases by increasing $\mathrm{Cu}^{+2}$ ion concentration up to $5 \mathrm{mmol} / \mathrm{l}$. Thereafter the graft yield decreases as $\mathrm{Cu}^{+2}$ ion concentration increase. In case of GMA the increase in grafting could be associated with the increase decomposition of $\mathrm{H}_{2} \mathrm{O}_{2}$ to yield $\mathrm{HO}_{2}^{-}$radicals which may be involved in the initiation of grafting (13) and to the increase in the number of free radicals formed on silk backbone. On the other hand, the decrease in graft yield by increasing $\mathrm{Cu}^{+2}$ ion concentration could be explained to the fast termination process. Figure 2 $(a, b)$ revealed that the homopolymer exhibit an opposite trend to graft yield as well as the graft efficiency and total conversion are similar to that of grafting.

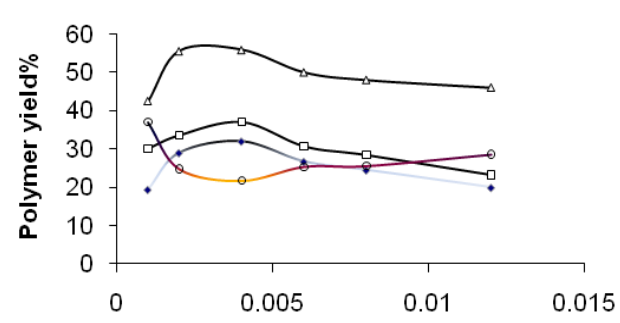

Copper sulfate concentration(m.mol/l)

Fig. 2(a). Effect of copper sulphate concentration on the polymer yield of grafted silk using GMA monomer

Conditions: 5\% GMA (o.w.f), $0.078 \mathrm{meq} / 1$ of hydrogen peroxide, time $1 \mathrm{hr}$., temperature $80{ }^{\circ} \mathrm{C}$, liquor ratio $1: 100$.

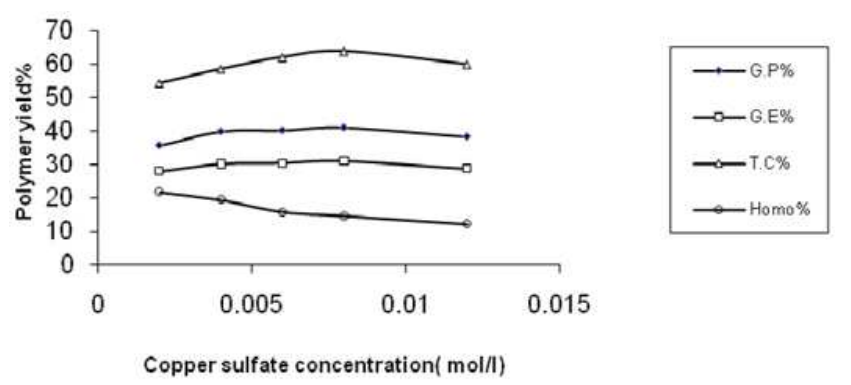

Fig. 2(b). Effect of copper sulphate concentration on the polymer yield of grafted silk using AA monomer.

Conditions: 5\%AA (o.w.f), $0.078 \mathrm{meq} / \mathrm{l}$ of hydrogen peroxide, time $1 \mathrm{hr}$., temperature $80^{\circ} \mathrm{C}$, liquor ratio $1: 100$.

\subsection{Monomer Concentration}

Figure $3(\mathrm{a}, \mathrm{b})$ shows the polymer yield percentage versus the monomer concentration when GMA and AA were used as monomers. With both monomers the results, show that increasing the monomer concentration is accompanied by a substantial increase of grafting where the graft yield decreases as monomer concentration increases. This can be referred to the depletion in monomer and initiator concentrations as well as reduction in the available sites for grafting on silk backbone as the reaction proceeds. The figure shows also that the homopolymer decreases with increasing both monomer GMA and AA.

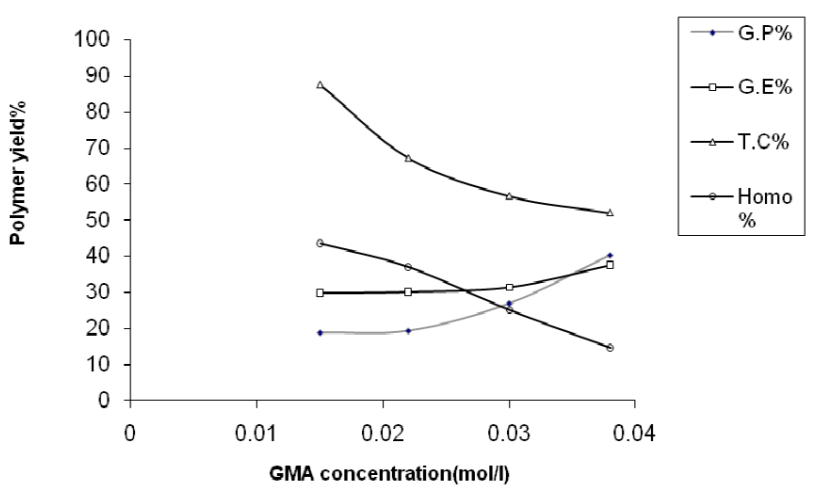

Fig. 3(a). Effect of GMA concentration on the polymer yield \% of grafted silk.

Conditions: Hydrogen peroxide $0.078 \mathrm{meq} / 1$, copper sulphate $5 \mathrm{mmol} / \mathrm{l}$, time $1 \mathrm{hr}$., temperature $80^{\circ} \mathrm{C}$, liquor ratio $1: 100$.

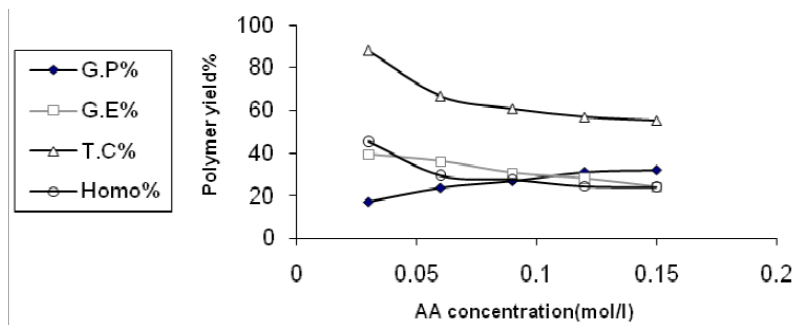

Fig. 3(b). Effect of acrylic acid concentration on the polymer yield \% of grafted silk. 
Conditions: Hydrogen peroxide $0.078 \mathrm{meq} / 1$, copper sulphate $5 \mathrm{mmol} / \mathrm{l}$, time $1 \mathrm{hr}$, , temperature $80^{\circ} \mathrm{C}$, liquor ratio $1: 100$.

\subsection{Polymerization Temperature}

The grafting of GMA and AA into silk was performed at various temperatures $\left(30-80{ }^{\circ} \mathrm{C}\right)$ and the results obtained are presented in Figure $4(a, b)$. It is obvious that the graft yield increases by raising the polymerization temperature from 30 ${ }^{\circ} \mathrm{C}$ to $70{ }^{\circ} \mathrm{C}$ for GMA and from $30{ }^{\circ} \mathrm{C}$ to $60{ }^{\circ} \mathrm{C}$ for AA. Further increase in the reaction temperatures lead to decrease in the graft yield. The increase in grafting by raising the temperature could be associated with the increase in the number of free radicals formed in the silk backbone and increase in propagation of grafting. Also, there is an increase in the mobility of monomer molecules and there collision with silk macroradicals (14).

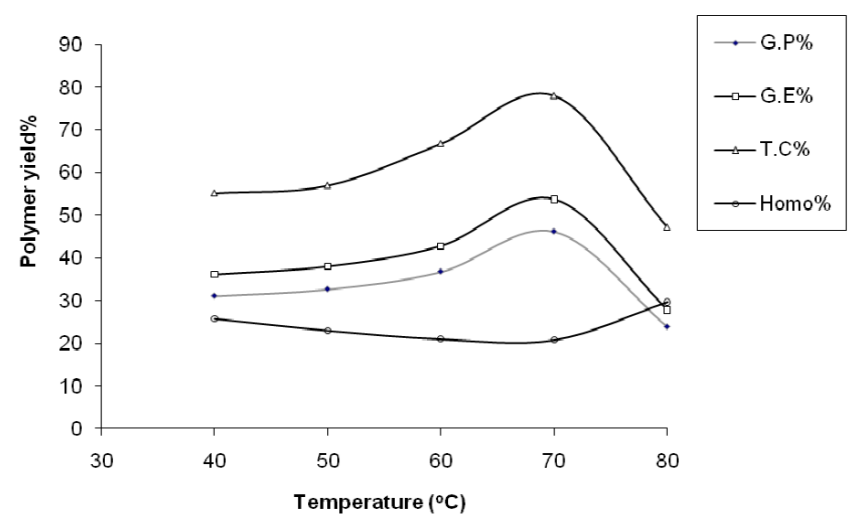

Fig. 4(a). Effect of temperature on the percentage polymer yield of grafted silk using GMA monomer.

Conditions: 5\% GMA; hydrogen peroxide $0.078 \mathrm{meq} / \mathrm{l}$; copper sulphate $5 \mathrm{mmol} / \mathrm{l}$; time $1 \mathrm{hr}$. and liquor ratio 1:100.

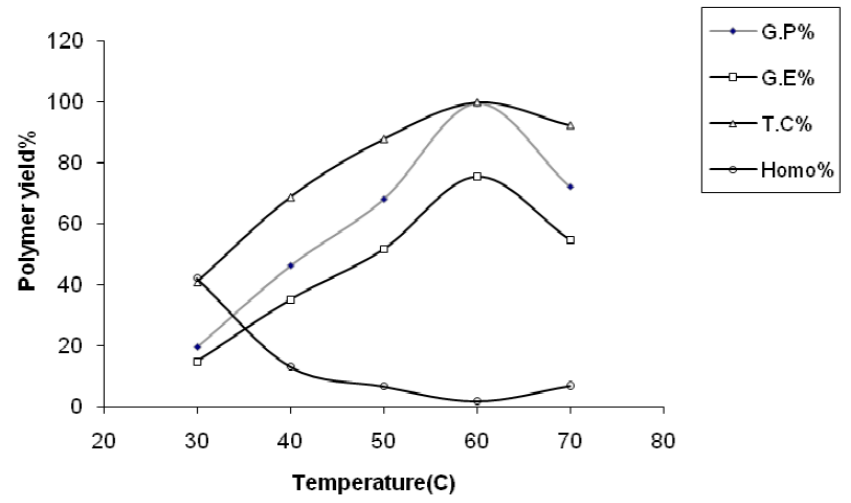

Fig. 4(b). Effect of temperature on the percentage polymer yield of grafted silk using AA monomers.

Conditions: 5\% AA ; hydrogen peroxide $0.078 \mathrm{meq} / \mathrm{l}$, copper sulphate $5 \mathrm{mmol} / \mathrm{l}$, time $1 \mathrm{hr}$. and liquor ratio $1: 100$.

\subsection{Polymerization Time}

Figures $5(\mathrm{a}, \mathrm{b})$ show the percentage polymer yield as a function of duration of polymerization. It is seen that the percentage polymer yield increases in case of GMA by prolonging the duration of polymerization within the range studied. It is expected that the homopolymer tends to decrease after about $45 \mathrm{~min}$. This indicates that the polymerization time exert a favorable effect on grafting and consequently on the grafting efficiency. In case of AA there is a tendency for the graft to decrease by increasing the time of contacts and namely the monomer to the silk. As a result the polymer yields decrease. This includes the trend observed with grafting.

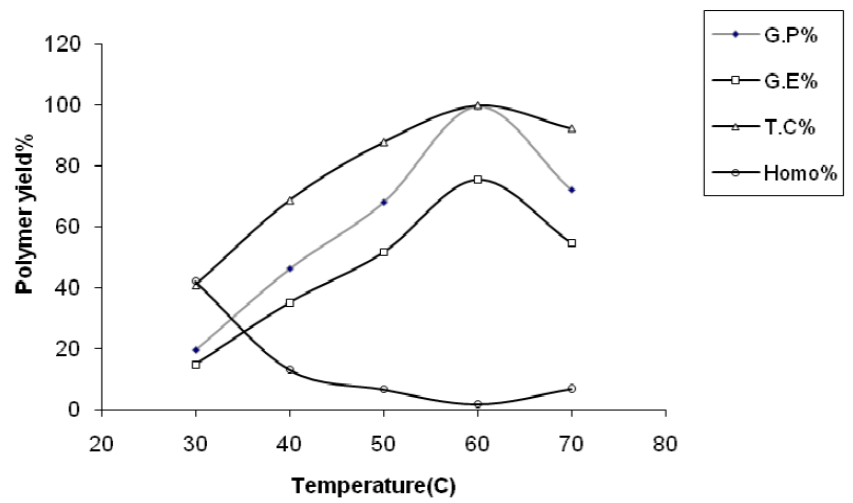

Fig. 5(a). Effect of duration on the polymer yield of grafted silk using GMA monomer.

Conditions: 5\% GMA; hydrogen peroxide $0.078 \mathrm{meq} / 1$; copper sulphate $5 \mathrm{mmol} / \mathrm{l}$ and liquor ratio 1:100.

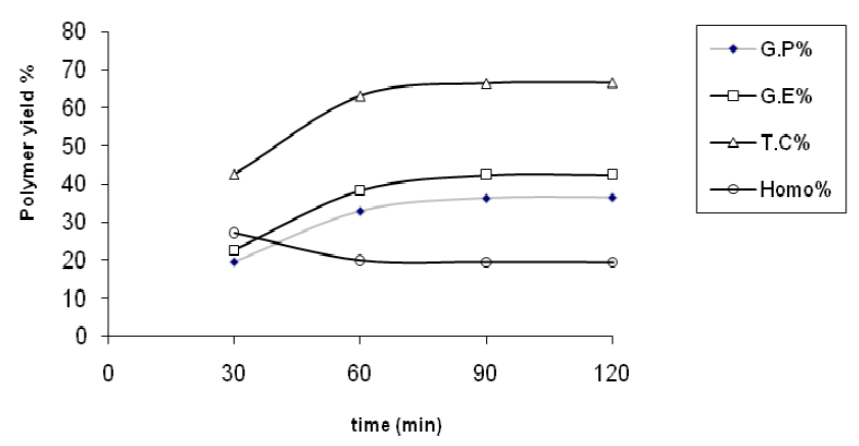

Fig. 5(b). Effect of time on the percentage polymer yield of grafted silk using AA monomer.

Conditions: 5\% GMA; hydrogen peroxide $0.078 \mathrm{meq} / \mathrm{l}$; copper sulphate $5 \mathrm{mmol} / \mathrm{l}$ and liquor ratio 1:100.

\subsection{Effect of GMA/AA Mixture on the Percentage Grafted Yield}

Based on the investigation observed, it may be concluded that the most appropriate conditions for GMA graft copolymerization onto the silk fabrics comprise $\mathrm{H}_{2} \mathrm{O}_{2} 0.078$ meq $/ 1$, copper sulphate $5 \mathrm{mmole} / \mathrm{L}$, GMA $0.03 \mathrm{~mol} / 1$ at $60{ }^{\circ} \mathrm{C}$ for $60 \mathrm{~min}$. and the material to liquor ratio 1:100 which are employed. The application of GMA /AA mixture of monomers onto silk fabric was used to obtain silk with different graft yields. Table 1 show that the extent of increased grafting depends on the ratio of AA in monomer ratio with GMA. This may be assumed to presence of 
epoxide ring in acidic medium and its change to hydroxyl group leading to increase graft yield.

Table 1. Effect of GMA /AA mixture on the percentage graft yield on Silk fabrics

\begin{tabular}{llll}
\hline \multicolumn{2}{l}{ GMA/AA ratio $(\mathbf{m o l} / \mathbf{l})$} & \multirow{2}{*}{ G.P \% } & G.E \% \\
\hline GMA & AA & & 22.7 \\
\hline 0.03 & ----- & 19.44 & 14.5 \\
0.03 & 0.03 & 24.9 & 13.5 \\
0.03 & 0.06 & 28.9 & 11.1 \\
0.03 & 0.09 & 46.9 & \\
\hline
\end{tabular}

\subsection{Dyeing Properties}

\subsubsection{Effect of Percentage (GMA) Grafted onto Silk Dyeability with Remazol Dye by Alkaline Method}

Table 2 and Figure 6 show the epoxy content the exhaustion and the fixation percentage of Remazol dye in alkaline medium onto silk sample grafted with GMA. It is evident that the grafted samples are much accessible to dyeing than untreated samples. This can be attributed to the lower stability and ring opening with alkaline media occur or via addition of $\mathrm{H}_{2} \mathrm{O}$ molecules to the free epoxy ring according to the typical $\mathrm{SN}^{2}$ mechanism (15).

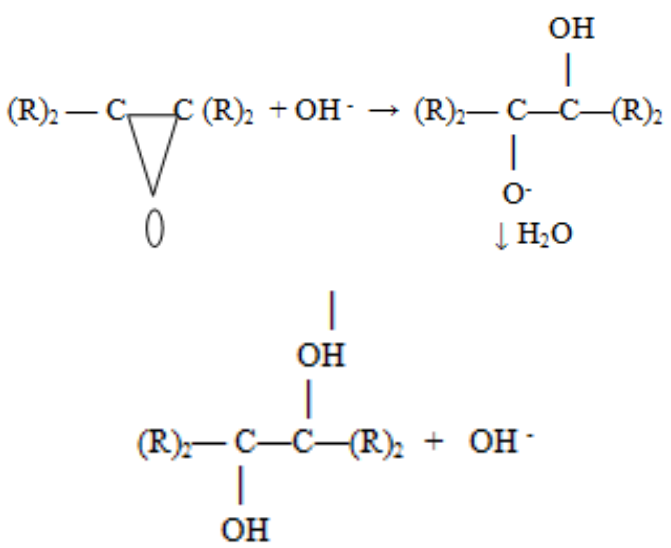

Equation 8 is the fast, so it is reasonable that silk ion is substituted for $\mathrm{OH}$ ion and the reaction represent as follows<smiles>[R10]C([14CH3])([14CH3])O</smiles>

Table 2. Effect of grafted polymerization of GMA with silk on fixation of Remazol Brill Blue $3 R$ dye

\begin{tabular}{lll}
\hline $\begin{array}{l}\text { Polymer addition based on increase in } \\
\text { weight \% }\end{array}$ & $\begin{array}{l}\text { Calculated epoxy content based on increase in } \\
\text { weight mol epoxy /100g }\end{array}$ & $\begin{array}{l}\text { Fixation of Remazol Brill Blue 3R in alkaline } \\
\text { medium }\end{array}$ \\
\hline- & - & 71.6 \\
14.5 & 0.131 & 73.2 \\
23.88 & 0.168 & 74.8 \\
32.44 & 0.172 & 81.2 \\
54.08 & 0.247 & 89.1 \\
72.1 & 0.275 & 94.3 \\
\hline
\end{tabular}

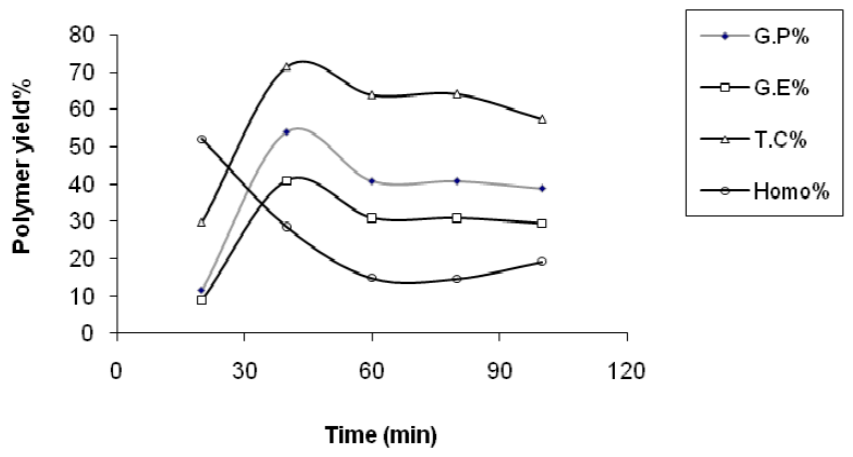

Fig. 6. Effect of grafted silk using GMA on dyeability with Remazol Brill Blue $3 R$ dye

\subsubsection{Acid Dyes}

Table 3 and Figures 7, 8 show epoxy content, percentage exhaustion and fixation of acid dyes obtained on grafted silk with poly GMA and the control, when they are dyed with acid dyes. In dyeing silk with acid dye, the dye molecule attached to silk by ionic bonds, but it observed from the study with both acid dyes that the exhaustion increases by increasing the time. In case of polyGMA grafted silk the same trend is also observed compared to control, but the latter shows a much slower rate of dyeing. This is due to the introduction of epoxide group into silk fibroin molecules in acidic medium of $\mathrm{pH} 3$ and the change of epoxide group to hydroxyl group causing an increase to positive silk surface potential. As a result the capability of grafted silk to absorb dye is increased. This reflects the effect of the nature of the dye and its affinity for silk fibroin. It appears that higher grafting polymer chains open up the silk structure. The rate of dyeing is also depending on the nature of dye, higher rate was found with both Supranol Blue B.L.W and Supranol Red G. W. 
Table 3. Effect of GMA graft polymerization with silk for fixation of acid dyes.

\begin{tabular}{llll}
\hline \multirow{2}{*}{$\begin{array}{l}\text { Polymer addition based on increase } \\
\text { in weight \% }\end{array}$} & $\begin{array}{l}\text { Calculated epoxy content based in } \\
\text { weight mol epoxy /100g }\end{array}$ & \multicolumn{2}{l}{ Fixation of acid dyes } \\
\cline { 3 - 4 } & - & Supranol Red G.W & Supranol Blue B.L.W \\
\hline- & 0.121 & 64.4 & 70.2 \\
19.5 & 0.134 & 70.1 & 76.1 \\
23.88 & 0.172 & 72.2 & 77.8 \\
32.44 & 0.247 & 76.2 & 78.2 \\
54.08 & 0.275 & 81.3 & 82.8 \\
\hline 2.1 & & 89.8 & 92.1 \\
\hline
\end{tabular}

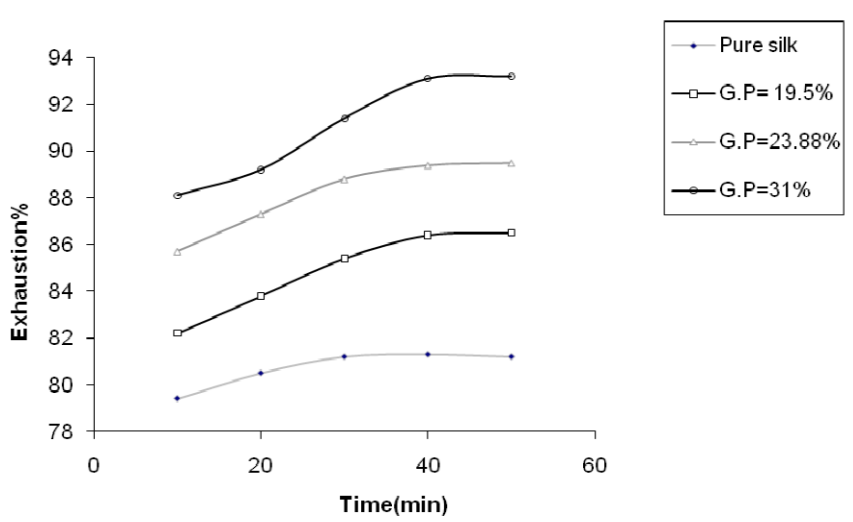

Fig. 7. Effect of grafted silk using GMA on dyeability with Supranol Red G. $W$

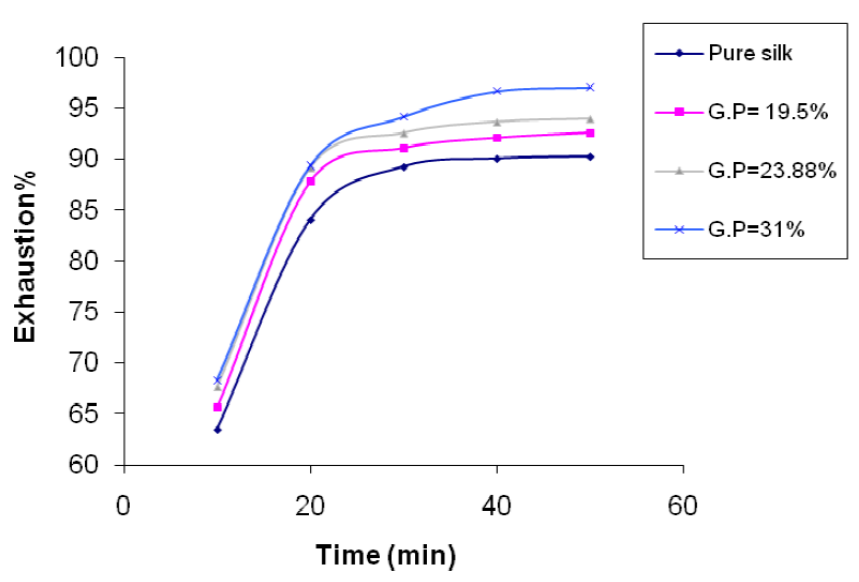

Fig. 8. Effect of GMA grafted silk on dyeability with Supranol BlueB. L. W

\subsection{Crease Recovery Angle}

The samples that were used in the study are given in Table 4 , from these results it is clear that grafted samples exhibit higher dry crease recovery than untreated samples. Differences in the application conditions seem to be responsible for the presence of poly (GMA) and poly (AA) graft copolymers which induce stabilization of the fabric in the dry state by virtue of involvement in reaction of silk and provide the fabric with the observed extra dry crease recovery.
Table 4. Effect of application of poly (AA) and poly (GMA) and their mixture grafting copolymers on the crease recovery angle (CRA) and the moisture regain properties of silk fabric.

\begin{tabular}{lllll}
\hline Sample & $\left(\mathbf{F}^{\mathbf{0}}\right)$ & $\left(\mathbf{W}^{\mathbf{0}}\right)$ & $\begin{array}{l}\text { C.R.A } \\
\left(\mathbf{F}^{\mathbf{0}}+\mathbf{W}^{\mathbf{0}}\right)\end{array}$ & $\begin{array}{l}\text { Moisture } \\
\text { regain \% }\end{array}$ \\
\hline Blank (untreated silk) & 106 & 127 & 233 & 10.6 \\
GMA/Silk (19.5\%) & 129 & 135 & 264 & 9.6 \\
GMA/Silk (23.88\%) & 136 & 140 & 276 & 8.8 \\
GMA/Silk (31\%) & 157 & 162 & 319 & 7.3 \\
AA/Silk (19.4\%) & 130 & 141 & 271 & 11.6 \\
AA/Silk (25\%) & 144 & 156 & 300 & 14.1 \\
AA/Silk (28.9) & 158 & 160 & 318 & 15.7 \\
GMA/AA/Silk (1:1) & 127 & 139 & 266 & 10.9 \\
GMA/AA/Silk (1:2) & 155 & 160 & 315 & 11.3 \\
GMA/AA/Silk (1:3) & 159 & 165 & 324 & 12.1 \\
\hline
\end{tabular}

\subsection{Moisture Regains}

Water content is an important physical parameter together with other factors, which can significantly influence the behavior of silk (i.e. comfort, crease recovery, etc.). Changes in percentage moisture regain induced on silk via grafting with GMA, AA and their mixture were studied as a function of weight gain. The relative humidity of silk is $11 \%$ but it is observed from Table 4 that grafting of GMA onto silk decreases the moisture regain to $7.3 \%$ or $31 \%$ GP. This may be attributed to addition of more hydrophobic poly (GMA) chains on fiber surface which limit the chemical and physical interactions with silk fibroin chains at the boundary contacts. Poly (AA) is hydrophilic in nature and enhances moisture absorption demonstrated by positive slope of the curve, whereas the intermediate properties of poly GMA/AA mixture do not significantly influence the balance of absorbed moisture.

\section{Conclusion}

The results reported in this work indicated that acrylic acid and glycidyl methacrylate or their mixture could be successfully grafted onto silk using $\mathrm{Cu}^{+2} / \mathrm{H}_{2} \mathrm{O}_{2}$ redox system. The grafting degree can be turned by altering monomer, initiator concentration and reaction time. 
The physical properties of silk were improved by grafting including crease recovery angle, moisture regain and dyeability as compared to the untreated one.

\section{References}

[1] Hu C., Yejuan T. \& kai S. Easy-care finishing of silk fabrics with a novel multifunctional epoxide. Part 2. J. Soc. Dye. \& col. 116 (2000) 204-207.

[2] Zaisheng C. , Guochuan J. \& Shaojun Y. Chemical finishing of silk fabric. Caloration Technology.117 (2001) 161-165.

[3] Tsukada M., Arai T., Freddi G., Imai T. \& kasai N. Grafting Vinyl Monomers Onto Silk Using Different Initiators: Properties of Grafted Silk J.Appl.Polym,Sci. 81 (2001) 14011409.

[4] Kawahara Y., Shioya M. \& Takaku A. Effects of nonformaldehyde finishing process on dyeing and mechanical properties of cotton fabrics. Am. Dyest. Rep. 85 (1996) 88.

[5] Das A., Saikia C.N. \& Hussaain S. Grafting of methyl methacrylate (MMA) onto Antheraea assama silk fiber. J Appl. polym. Sci. 81 (2001) 2633-2641.

[6] Tsukada M., Imai T., Freddi G., Lenka S. \& Kasai N. Grafting of vinyl Monomer onto Silk Using Redox System. Yellowing of Silk. J.Appl.Polym.Sci. 69 (1998), 239-246.

[7] Bendak A., Abdel-Fattah S.H. \& Hebeish A. Graft Copolymerization of Vinyl Monomer Onto Wool Fibers. Die AngewMakro. 43 (1975) 11-25.
[8] Steitn H. H. \& Guarnaccio J. Infrared Study of Oxidized Keratin Text. Res. J. 29 (1959) 492-496.

[9] Hebeish A. \& Bendak A. Redox-initiated vinyl graft polymerization onto wool with thiourea as the reductant. I. Grafting of methyl methacrylate with the hydrogen peroxidethiourea catalyst system. J. Appl. Polym. Sci. 18 (1974) 13051317.

[10] EL-Rafie M.H., Khalil M.I. \& Hebeish A. Graft Copolymerization of vinyl Monomers on Modified Cotton, Die Angew.Makromol Chem 37(1974) 149-160.

[11] Patel A. C., Brahmbhatt R. B., Jain R.C. \& Devi S. Grafting of 2-HEMA on IPP and in situ chlorinated PP through solution polymerization J. Appl.Polym.Sci. 69 (1998) 2107-2113.

[12] Hebeish A. \& Bendak A. Redox-initiated vinyl graft polymerization onto wool with thiourea as the reductant. I. Grafting of methyl methacrylate with the hydrogen peroxidethiourea catalyst system. J. Appl. Polym.Sci. 18 (1974) 13051317.

[13] Tsukada M. \& Freddi G. Absorption of metal cations by modified mori silk and preparation of Fabrics with Antimicrobial Activity. Polym.Material Encyclopedia 10 (1996) 7728 .

[14] Harris J.A. \& Arthur J.C. Single Dye bath Application of Direct, Acid, and Basic Dyes to Cotton-Poly (Glycidyl Methacrylate) Fabrics. Text. Res. J. 46 (1976) 219-223.

[15] Hamerton. I. Recent Developments in Epoxy Resins. Smithers Rapra Publishing (1996)176 pp. 